Case Report

\title{
Stunting, Micronutrient Deficiencies, and Worm Infections Among Primary School Children at Low and Lower-Middle Income Countries in Asia and Africa: A Systematic Review
}

\author{
Fauzi Budi Satria ${ }^{1, *}$, Le Thi Huong ${ }^{2}$, Odilia Isabel Bermudez ${ }^{3}$ \\ ${ }^{1}$ School of Preventive Medicine and Public Health, Hanoi Medical University, Hanoi, Vietnam \\ ${ }^{2}$ Department of Nutrition and Food Safety, Hanoi Medical University, Hanoi, Vietnam \\ ${ }^{3}$ Department of Public Health and Community Medicine, Tufts University, Boston, United States
}

\section{Email address:}

fauzibudisatria@gmail.com (F. B. Satria), lethihuong@hmu.vn.edu (Le T. Huong), odilia.bermudez@tufts.edu (O. I. Bermudez)

${ }^{*}$ Corresponding author

\section{To cite this article:}

Fauzi Budi Satria, Le Thi Huong, Odilia Isabel Bermudez. Stunting, Micronutrient Deficiencies, and Worm Infections Among Primary School Children at Low and Lower-Middle Income Countries in Asia and Africa: A Systematic Review. Central African Journal of Public Health. Vol. 4, No. 4, 2018, pp. 102-111. doi: 10.11648/j.cajph.20180404.12

Received: July 7, 2018; Accepted: August 2, 2018; Published: August 28, 2018

\begin{abstract}
Most of stunting and children with micronutrient deficiencies lived in Asia and in Africa region. In many developing countries, any nutritional disorders are aggravated by some infectious diseases such as worm infections especially among children aged 5 to 15 years. The aim of this review study was to describe and compare the prevalence of stunting, micronutrient deficiencies, and worm infections prevalence among primary school children at low and lower-middle income countries in Asia and Africa from 2007 to 2017. The methodology of this research was systematic review, with target population is primary school children aged 6-15 years. The resources of this review study came from online and offline databases; included PubMed, Cochrane Library, Google and Google Scholars. Selected studies should be published journals from low and low-middle income countries in Asia and Africa in last 10 years. A total of 450 selected articles from the various resources were exported to Endnote. Then all the references were filtered by reading the tittles to exclude duplicate resources and the abstracts to exclude resources with unmatched criteria such as children's age range. Remaining references then were appraised by using appraisal tool and extraction tools from JBI. All these steps were recorded in PRISMA flow diagram (figure 1). Finally, there were 57 of 450 references were selected in this review study. The result of this research showed the prevalence of stunting and micronutrient deficiencies among primary school children in low income countries was higher from Asia. Meanwhile, in lower-middle income countries stunting and micronutrient deficiencies prevalence among primary school children were higher in Africa. Different to stunting and micronutrient deficiencies, prevalence of worm infections in both income country groups was higher in Africa than in Asia. Based on the region, more stunting primary school children were found in Asia than Africa. In contrast, prevalence of micronutrient deficiencies and worm infections were higher among primary school children from Africa. Based on income country group, prevalence of stunting was slightly similar in low and lower-middle income countries. On the other hand, prevalence of micronutrient deficiencies and worm infections were much higher in primary school children from low income countries. In conclusion, this researched stated that primary school children in Asia and Africa have the same nutritional problems and economic level of a country can't be a single variable to describe the burden of stunting, micronutrient deficiencies, and worm infections among primary school children.
\end{abstract}

Keywords: Stunting, Micronutrient Deficiencies, Worm Infections, Primary School Children, Low Income Countries, Lower-Middle Income Countries, Asia, Africa 


\section{Introduction}

Stunting is the devastating result of poor nutrition in early childhood and the effect can last a lifetime [61]. Most of stunting children lived in Asia Africa region [61]. Not only stunting, micronutrient deficiencies are also affected the children in developing countries in Asia and Africa. In many developing countries, any nutritional disorders are aggravated by some infectious diseases [64]. One of most common infectious diseases in children is worm infections and the highest prevalence was found in 5 to 15 years of age children [65]. In long term, worm infections showed the delayed in growth and physical development in children [62]. This review study is expected to describe and compare the prevalence of stunting, micronutrient deficiencies, and worm infections prevalence among primary school children at low and lower-middle income countries in Asia and Africa from 2007 to 2017.

\section{Materials and Methods}

This systematic review study collected and analyzed multiple literatures from researches or papers critically. Then, we summarized all evidences from references that matched to criteria in this study to answer research question in this study [15]. In this study, all references with children population in age range of 6 to 15 years will be included. The references should also have the same criteria in determine stunting, micronutrient deficiencies, and worm infections condition in children. This review study defined stunting children as child's physical condition with anthropometry measurement in height-for-age WHO growth charts showed Z-score below -2 SD. Next, micronutrient deficiencies is defined as deficiency in Vitamin A, iron, and zinc among children. Then, worm infections is defined as worm infections that caused by 3 types of worm; nematodes, trematodes, or cestodes. Lastly, all the references should from low and lower-middle income countries in Asia and Africa based on World Bank list.

There are some other criteria for the references to be included in this review study. First, the references should have been published in peer reviewed journal in the last ten years (2007-2017). PUBMED/MEDLINE, Cochrane Library, Google Scholars and Google were online search engines that had been used in this review study to collect the references. Beside from online resources, journals in both printed and PDF file version which meet the criteria for this study were included. Then, all the references also should be available in full text English version. Then, the resources should show the prevalence of stunting, micronutrient deficiencies, and worm infections among primary school children to give evidence about those conditions, so this review study will be able to answer the research question.

This study used some techniques to find suitable resources from online databases. Boolean Logic technique was used in PUBMED/MEDLINE search engine. Then, MeSH (Medical Sub Heading) was used for Cochrane library, and typing suitable keywords is used for Google. Keywords and their synonyms for stunting, micronutrient deficiencies and/or worm infections among primary school children in low and lower-middle income countries in Asia and Africa were used for any search techniques in online search engines. In the filter sections, last ten years full text published journals and available in English version were chosen. Then, all studies from online databases were imported to Endnote to make it easier in calculating the total documents were chosen and to make doing citation easier later.

Next, critical appraisal framework and data extraction form from the Joanna Briggs Institute (JBI) was used as a guide to assess the quality of studies reviewed [30, 31]. Then, the data extraction result was discussed with independent reviewer. Finally, based on the discussion with independent viewer, a table list of included final selected resources and the data from those references were developed. Total of 450 selected articles from the various resources were exported to Endnote and recorded in PRISMA flow diagram. From those 450 resources, 393 articles were removed due to several factors such as duplication, inappropriate study setting, published year, sample's age range and study result. Total 57 articles were selected in this study. The step of selected the references for this study was recorded and recorded in a PRISMA flow diagram, as can be seen in figure 1 below. 


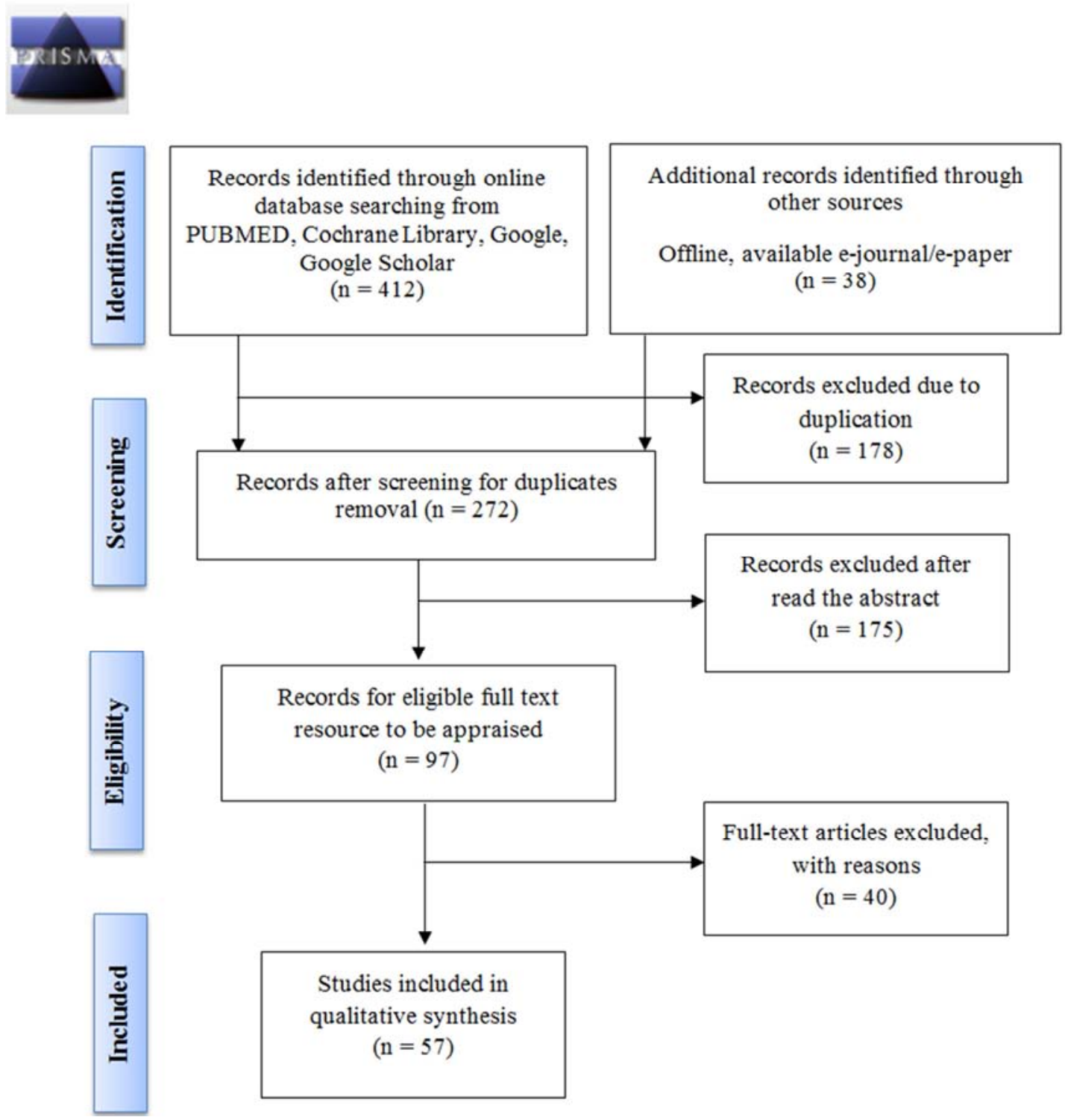

Figure 1. PRISMA 2009 Flow Diagram.

\section{Result}

\subsection{Stunting}

The description of stunting among primary school children in some low and lower-middle income countries in Asia and Africa is assessed by the prevalence of 6 to 15 years of age children with Z-score below -2 SD in WHO Growth Charts based on anthropometry measurements. The summary table has been developed to show description of stunting among primary children in low and lower-middle income countries in Asia and Africa (Table 1).

Table 1. Description of stunting among primary school children.

\begin{tabular}{|c|c|c|c|c|}
\hline Income Country Group/ Region & Country & $\begin{array}{l}\text { Population Group } \\
\text { (Aged years) }\end{array}$ & $\begin{array}{l}\text { Sample (Aged 6-15 } \\
\text { years) }\end{array}$ & $\begin{array}{l}\text { Stunting Prevalence } \\
(\%)\end{array}$ \\
\hline \multirow{3}{*}{ Low Income Country/ Asia } & Nepal [43] & $6-12$ & 125 & 34.4 \\
\hline & Nepal [47] & $9-13$ & 287 & 56.1 \\
\hline & Nepal [58] & $6-8$ & 3356 & 45.4 \\
\hline \multirow{3}{*}{ Low Income Country/ Africa } & Ethiopia [24] & $5-18$ & 1368 & 10.0 \\
\hline & Ethiopia [19] & $6-14$ & 523 & 46.1 \\
\hline & Ethiopia [37] & $6-15$ & 587 & 34.6 \\
\hline
\end{tabular}




\begin{tabular}{lllll}
\hline Income Country Group/ Region & Country & $\begin{array}{l}\text { Population Group } \\
\text { (Aged years) }\end{array}$ & $\begin{array}{l}\text { Sample (Aged 6-15 } \\
\text { years) }\end{array}$ & $\begin{array}{l}\text { Stunting Prevalence } \\
\text { (\%) }\end{array}$ \\
\hline & Ethiopia [26] & $7-17$ & 7431 & 22.2 \\
& Ethiopia [1] & $6-14$ & 356 & 13.5 \\
& Uganda [36] & $6-14$ & 432 & 22.5 \\
& Burkina Faso [17] & $8-14$ & 385 & 29.4 \\
& Tanzania [52] & $7-14$ & 845 & 30.0 \\
& Sri Lanka [42] & $5-10$ & 4021 & 26.0 \\
& Sri Lanka [18] & $1-15$ & 341 & 22.0 \\
Lower-middle Income Country/ Asia & Bangladesh [55] & $6-9$ & 571 & 25.5 \\
& Vietnam [45] & $6-8$ & 510 & 49.2 \\
& Philippines [48] & $6-14$ & 693 & 57.5 \\
& Myanmar [49] & $5-19$ & 513 & 50.3 \\
& Nigeria [8] & $12-18$ & 169 & 19.6 \\
& Nigeria [56] & $5-19$ & 245 & 52.7 \\
& Nigeria [22] & $9-12$ & 2015 & 33.2 \\
& Nigeria [16] & 6 months to 15 years & 202 & 22.3 \\
& Ghana [7] & $6-13$ & 404 & 24.0 \\
\hline
\end{tabular}

\subsection{Micronutrient Deficiencies}

The description of micronutrient deficiencies among primary school children in some low and lower-middle income countries in Asia and Africa is assessed by the prevalence of 6 to 15 years children with deficiencies in Vitamin A, zinc, and/or iron. The resources summary of micronutrient deficiencies among primary school children has been drawn in table 2 below.

Table 2. Description of micronutrient deficiencies among primary school children.

\begin{tabular}{|c|c|c|c|c|c|c|}
\hline \multirow{2}{*}{ Income Country Group/ Region } & \multirow{2}{*}{ Country } & \multirow{2}{*}{$\begin{array}{l}\text { Population Group } \\
\text { (Aged years) }\end{array}$} & \multirow{2}{*}{$\begin{array}{l}\text { Total Sample } \\
\text { (Aged 6-15 years) }\end{array}$} & \multicolumn{3}{|c|}{ Prevalence of Micronutrient Deficiency (\%) } \\
\hline & & & & Vitamin A & Iron & Zinc \\
\hline Low Income Country/ Asia & Nepal [43] & $6-12$ & 125 & - & - & 85.6 \\
\hline \multirow{4}{*}{ Low Income Country/ Africa } & Tanzania [52] & $7-14$ & 798 & 31.9 & 32.7 & - \\
\hline & Ethiopia [14] & $6-12$ & 586 & - & 37.5 & - \\
\hline & Bangladesh [2] & $6-11$ & 368 & - & - & 39.1 \\
\hline & Bangladesh [50] & $6-15$ & 352 & 29 & 43.9 & - \\
\hline Lower-middle Income & Sri Lanka [6] & $6-19$ & 2281 & - & 14.7 & - \\
\hline \multirow[t]{4}{*}{ Country/Asia } & India $[25]$ & $6-16$ & 1247 & 2.0 & - & - \\
\hline & Vietnam [44] & $6-8$ & 510 & 11.2 & 5.1 & 55.8 \\
\hline & Vietnam [12] & $6-9$ & 510 & 10.2 & 0.8 & 70.6 \\
\hline & Nigeria [8] & $12-18$ & 13 & 46.2 & 76.9 & - \\
\hline \multirow{3}{*}{$\begin{array}{l}\text { Lower-middle Income Country/ } \\
\text { Africa }\end{array}$} & Kenya [11] & $9-12$ & 206 & - & - & 21.0 \\
\hline & Ghana [21] & $6-12$ & 142 & 93.6 & - & - \\
\hline & Ghana [5] & $14-15$ & 188 & 36.0 & 4 & - \\
\hline
\end{tabular}

\subsection{Worm Infections}

The description of worm infections among primary school children in some low and lower-middle income countries in Asia and Africa is assessed by the prevalence of 6 to 15 years children with worm infections caused by nematodes, cestodes, and/or trematodes. Total 34 resources have been collected to describe the prevalence of worm infection among primary school children in low and lower-middle income countries from Asia and Africa. Table 3 has been built to give summary of included resources of worm infections among primary school children in low and lower-middle income countries in Asia and Africa.

Table 3. Description of worm infections among primary school children.

\begin{tabular}{|c|c|c|c|c|c|c|}
\hline \multirow{2}{*}{$\begin{array}{l}\text { Low Income Country } \\
\text { / Region }\end{array}$} & \multirow{2}{*}{ Country } & \multirow{2}{*}{$\begin{array}{l}\text { Population Group } \\
\text { (Aged years) }\end{array}$} & \multirow{2}{*}{$\begin{array}{l}\text { Total Sample } \\
\text { (Aged 6-15 years) }\end{array}$} & \multicolumn{3}{|c|}{ Worm Infections Prevalence by Worm Type (\%) } \\
\hline & & & & Nematodes & Cestodes & Trematodes \\
\hline \multirow{5}{*}{$\begin{array}{l}\text { Low Income Country/ } \\
\text { Asia }\end{array}$} & Afghanistan [34] & $8-18$ & 1169 & 25.3 & 10.0 & 1 \\
\hline & Nepal [54] & $5-15$ & 928 & 2.3 & 1.7 & - \\
\hline & Nepal [51] & $9-12$ & 495 & 32.5 & 1.8 & - \\
\hline & Nepal [35] & $6-16$ & 114 & 13.1 & 3.5 & - \\
\hline & Nepal [53] & $12-15$ & 200 & 6.5 & 6.5 & - \\
\hline \multirow{5}{*}{$\begin{array}{l}\text { Low Income Country/ } \\
\text { Africa }\end{array}$} & Ethiopia [24] & $5-18$ & 138 & 17.0 & - & - \\
\hline & Ethiopia [19] & $6-14$ & 523 & 3.4 & - & - \\
\hline & Ethiopia [37] & $6-15$ & 583 & 26.0 & 14.0 & 22.0 \\
\hline & Ethiopia [60] & $5-15$ & 201 & 52.7 & - & 36.3 \\
\hline & Ethiopia [4] & $5-19$ & 370 & 39.2 & - & 59.7 \\
\hline
\end{tabular}




\begin{tabular}{|c|c|c|c|c|c|c|}
\hline \multirow{2}{*}{$\begin{array}{l}\text { Low Income Country } \\
\text { / Region }\end{array}$} & \multirow{2}{*}{ Country } & \multirow{2}{*}{$\begin{array}{l}\text { Population Group } \\
\text { (Aged years) }\end{array}$} & \multirow{2}{*}{$\begin{array}{l}\text { Total Sample } \\
\text { (Aged 6-15 years) }\end{array}$} & \multicolumn{3}{|c|}{ Worm Infections Prevalence by Worm Type (\%) } \\
\hline & & & & Nematodes & Cestodes & Trematodes \\
\hline & Ethiopia [66] & $5-15$ & 257 & 50.6 & 0.8 & 26.5 \\
\hline & Ethiopia [13] & $5-15$ & 170 & 51.8 & - & - \\
\hline & Uganda [36] & $6-14$ & 432 & 13.5 & - & 1.8 \\
\hline & Tanzania [39] & $4-15$ & 490 & - & - & 67.1 \\
\hline & Tanzania [52] & $7-14$ & 845 & 68.0 & - & 54.0 \\
\hline & Sierra Leone [27] & $9-14$ & 1760 & 35.2 & - & 40.2 \\
\hline & Burkina Faso [17] & $6-14$ & 385 & 0.8 & 6.5 & 4.2 \\
\hline & India [59] & $9-10$ & 646 & 59.6 & - & - \\
\hline & India [23] & $4-17$ & 590 & 42.5 & - & - \\
\hline & India [32] & $6-14$ & 3706 & 7.8 & - & - \\
\hline \multirow{8}{*}{$\begin{array}{l}\text { Lower-middle Income } \\
\text { Country/Asia }\end{array}$} & Philippines [28] & $8-11$ & 70 & 63.0 & - & - \\
\hline & Philippines [48] & $6-14$ & 667 & 25.6 & - & 2.0 \\
\hline & Vietnam [45] & $6-8$ & 510 & 65.4 & - & - \\
\hline & Vietnam [12] & $6-9$ & 510 & 80.2 & - & - \\
\hline & Palestine [29] & $7-13$ & 735 & 5.4 & - & - \\
\hline & Ghana [7] & $6-13$ & 404 & & - & 2.5 \\
\hline & Kenya [33] & $5-18$ & 2824 & 16.4 & - & - \\
\hline & Kenya [11] & $9-12$ & 206 & - & - & 51.5 \\
\hline \multirow{6}{*}{$\begin{array}{l}\text { Lower-middle Income } \\
\text { Country/Africa }\end{array}$} & Zambia [41] & $9-15$ & 214 & - & - & 93.0 \\
\hline & Nigeria [3] & $4-15$ & 572 & 25.5 & 9.6 & 47.2 \\
\hline & Nigeria [46] & $6-14$ & 316 & 82.3 & - & - \\
\hline & Cote d'Ivoire [40] & $7-15$ & 156 & - & - & 9.6 \\
\hline & Cote d'Ivoire [20] & $6-15$ & 112 & 55.4 & - & 83.0 \\
\hline & Angola [57] & $6-15$ & 1142 & 38.1 & 7.5 & - \\
\hline
\end{tabular}

\subsection{Comparison}

The comparison of stunting, micronutrient deficiencies, and worm infections among primary school children is assessed by comparing the prevalence of stunting, micronutrient deficiencies, and worm infections among primary school children between low and lower-middle income countries in Asia and Africa.

\subsubsection{Stunting, Micronutrient Deficiencies, and Worm Infections in Low and Lower-Middle Income Countries in Asia and Africa}

Figure 2 showed the comparison of stunting, micronutrient deficiencies, and worm infections prevalence between primary school children in low and lower-middle income countries from Asia and Africa. From the figure, it can be seen that stunting is higher among primary school children in low income countries from Asia than children from Africa. But, in lower-middle income countries, more primary school children from Africa suffered from stunting than children in Asia region. Similar to stunting prevalence, micronutrient deficiencies prevalence also showed the same trend. Higher prevalence of micronutrient deficiencies is higher among children from low income countries in Asia than children in Africa. Then, primary school children in low income countries from Africa have higher prevalence of micronutrient deficiencies than children from Asia region. For worm infections, the data showed that the prevalence of worm infections among primary school children is higher in Africa than Asia, in both income country groups.

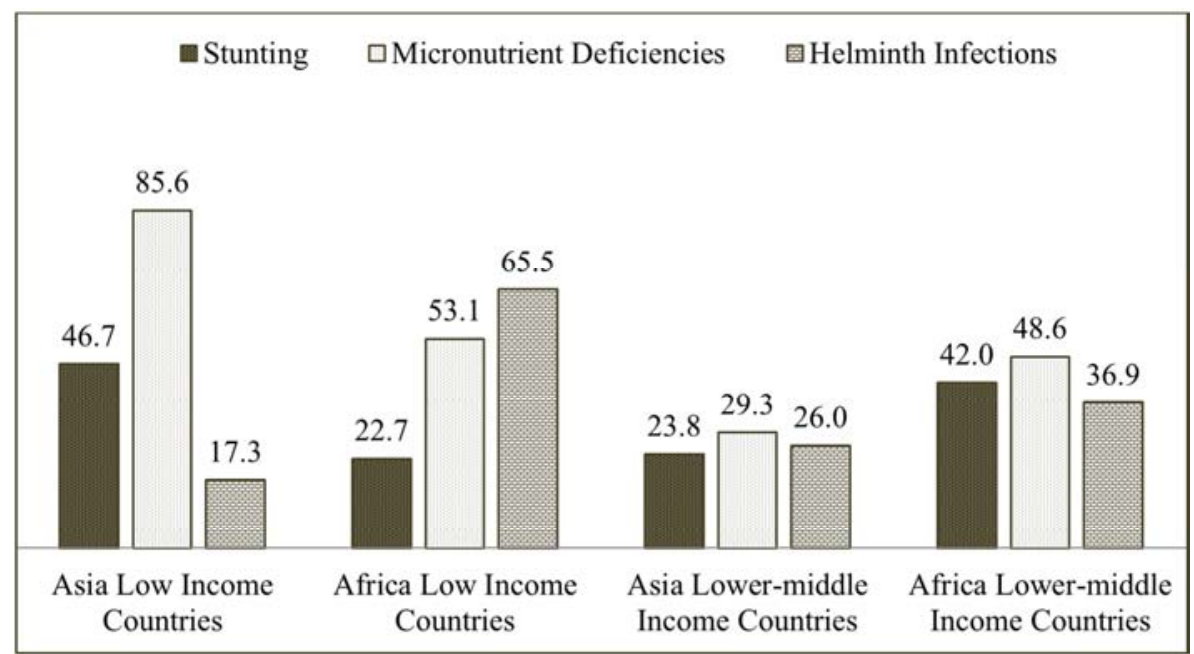

Figure 2. Comparison of stunting, micronutrient deficiencies, and worm infections prevalence between primary school children in low and lower-middle income countries from Asia and Africa. 


\subsubsection{Stunting, Micronutrient Deficiencies, and Worm Infections in Asia and Africa}

This review study also compares the prevalence of stunting, micronutrient deficiencies, and worm infections among primary school children between Asia and Africa region without considered their income group. All the resources from Asian countries are compared to all resources from African countries to describe the comparison of stunting, micronutrient deficiencies, and worm infections prevalence among primary school children. Based on the region, prevalence of micronutrient deficiencies and worm infections among primary school children are higher in Africa than Asia. In contrast, the prevalence of stunting among primary school children is higher in Asia than in Africa.

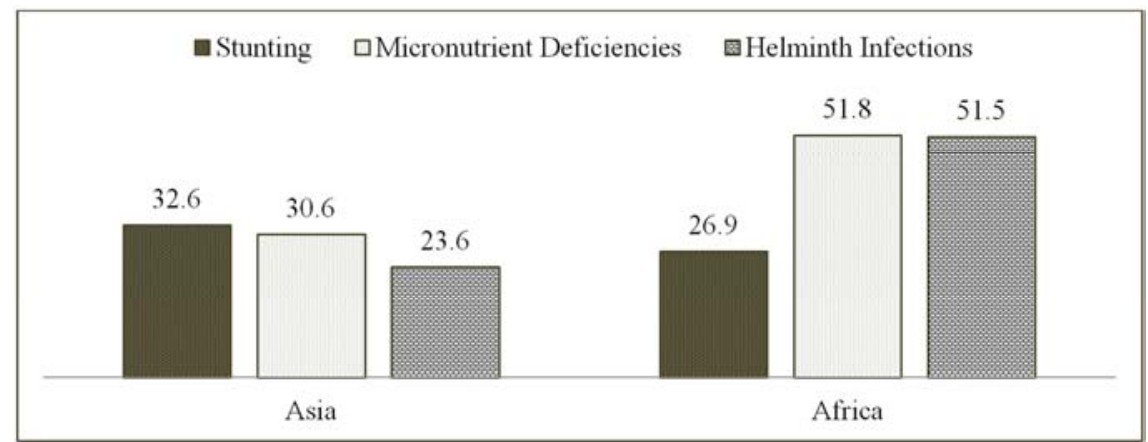

Figure 3. Comparison of stunting, micronutrient deficiencies, and worm infections prevalence between primary school children in Asia and Africa.

\subsubsection{Stunting, Micronutrient Deficiencies, and Worm Infections in Low and Lower-Middle Income Countries}

Based on income country group, this study divided it into two groups which are low and lower-middle income countries. The references for each group were taken from selected references from any countries in Asia and Africa. The result showed the prevalence of micronutrient deficiencies and worm infections among primary school children were higher in low income country group, while slight higher prevalence of stunting was higher in lower-middle income country group than low income country group.

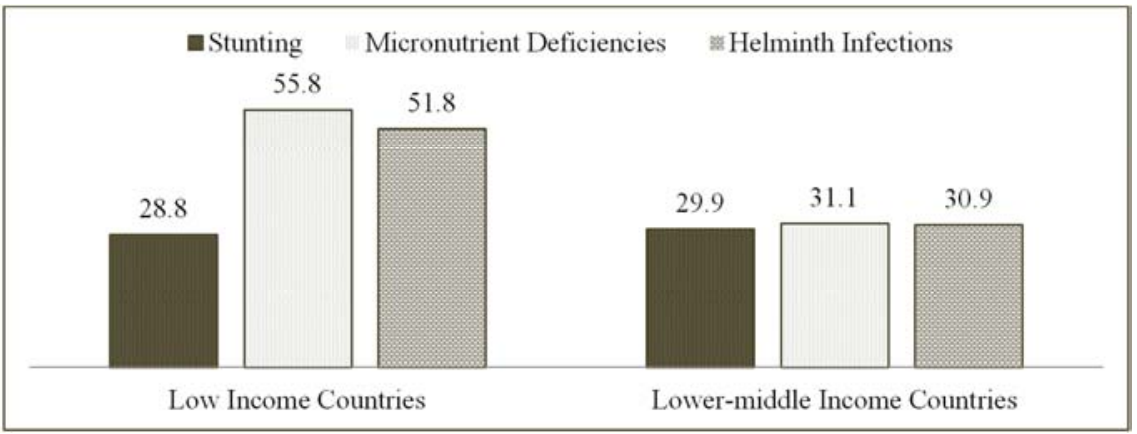

Figure 4. Comparison of stunting, micronutrient deficiencies, and worm infections prevalence between primary school children in low and lower-middle income countries.

Based on the type of micronutrient deficiencies, prevalence of iron deficiency was the highest in primary school children from low income countries, while zinc deficiency prevalence was the highest among primary school children in lower-middle income countries.

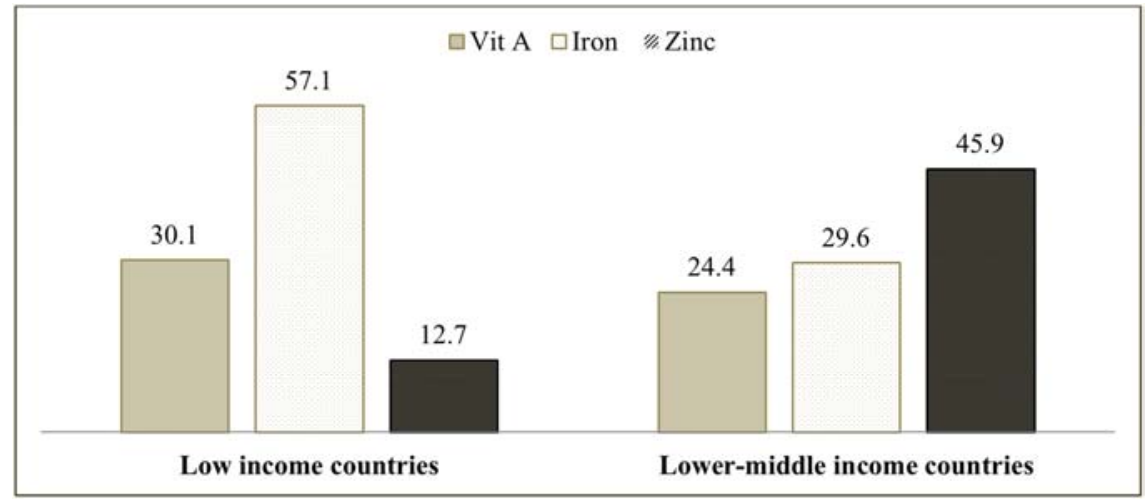

Figure 5. Comparison the type of micronutrient deficiencies prevalence between primary school children in low and lower-middle income countries. 
Lastly, based on the type of worm that infected the children, prevalence of nematodes infection was the highest in primary school children from low and lower-middle income country group, and followed by trematodes and cestodes infections.

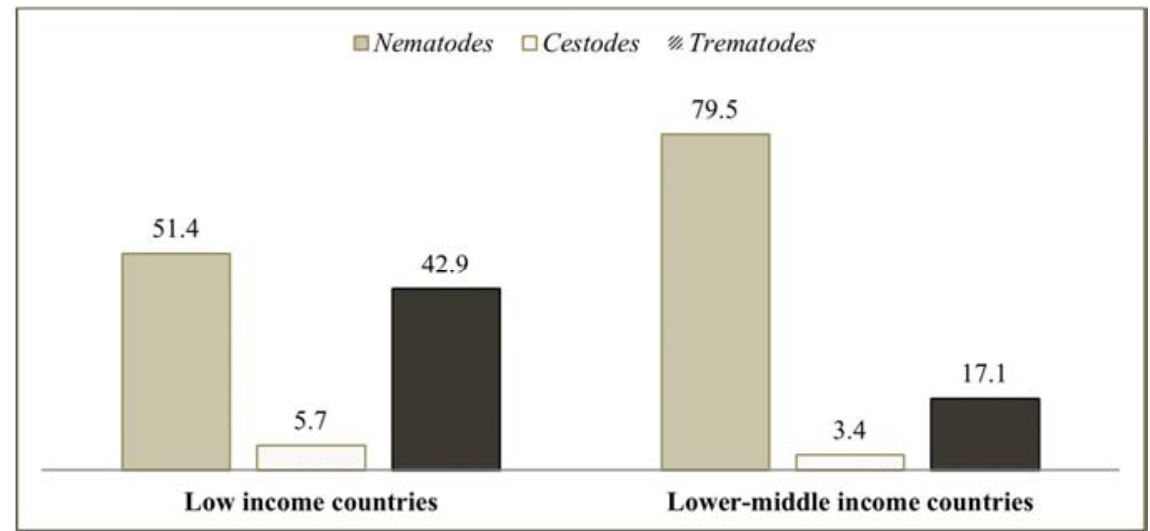

Figure 6. Comparison the type of worm infections prevalence between primary school children in low and lower-middle income countries.

\section{Discussion}

The prevalence of stunting among children aged below 5 years was higher in Asia than Africa [61]. This review study showed that among primary school-age children aged 6-15 years, stunting prevalence also was higher in Asia than in Africa.

In Asia, the highest prevalence of stunting children was found in Southern and Southeast region [2]. This report was relevant to this review study result, where all the references that contributed to the result of this review study were from both part of Asia. The countries such as Nepal, Afghanistan, Sri Lanka, and Bangladesh were located at South part of Asia, while Myanmar, Philippines, and Vietnam which also contributed in this review study result were located at Southeast part of Asia. There were no references in this review study came from the countries at other part of Asia.

It was reported that only Northern Africa which has low prevalence of stunting children [61]. This report was also relevant to the result of this review study. In this study, there were no references from North part of Africa showed stunting prevalence among primary school children.

Some references showed that the prevalence of micronutrient deficiencies such as iron deficiency, Vitamin A deficiency, and zinc deficiency was high in Africa and Asia specifically low income countries [9]. The result of this review study showed the same trend to the references. This review study showed the higher prevalence of micronutrient deficiencies was found in Africa than in Asia. Moreover, micronutrient deficiencies prevalence was also higher in low income country group than lower-middle income country group. Then, the prevalence of zinc deficiency was always high in any references which compared it with iron and vitamin A deficiency directly.

Many references showed that Worm infections were affected the poorest and most deprived communities mostly [63]. This review study showed that children who lived in the low income country group in Asia and Africa had higher prevalence of worm infections than children who lived at lower-middle income country group. Nematode is the most common type of worm that infected primary school children in low and lower-middle income country from Asia and Africa region. This high prevalence comes from all species which are categorized as nematodes worm, but mostly infections were caused by Schistosoma sp.

\section{Conclusion}

The prevalence of stunting, micronutrient deficiencies, and worm infections among primary school children (aged 6-15 years) has the identic trend as pre-school children (below 5 years of age). We concluded that children aged primary school children and pre-school children from low and lower-middle income countries in Asia and Africa have the same burden of stunting, micronutrient deficiencies, and worm infections.

\section{Limitation}

The result of this review study was highly influenced by the data resources which dominated by some particular countries in each country group and each region. Limitation also caused by age range of the population target in this review study. Most of studies were excluded due to variety of age range didn't meet the age range requirement for this review study.

\section{References}

[1] Abdi, M., Nibret, E., \& Munshea, A. (2017). Prevalence of intestinal helminthic infections and malnutrition among schoolchildren of the Zegie Peninsula, northwestern Ethiopia. $J$ Infect Public Health, 10 (1), 84-92. doi: 10.1016/j.jiph.2016.02.009.

[2] Adams, A. M., Ahmed, R., Latif, A. H., Rasheed, S., Das, S. K., Hasib, E., Faruque, A. (2017). Impact of fortified biscuits on micronutrient deficiencies among primary school children in Bangladesh. PLoS One, 12 (4), e0174673. doi: 10.1371/journal.pone.0174673. 
[3] Adedoja, A., Tijani, B. D., Akanbi, A. A., 2nd, Ojurongbe, T. A., Adeyeba, O. A., \& Ojurongbe, O. (2015). Co-endemicity of Plasmodium falciparum and Intestinal Helminths Infection in School Age Children in Rural Communities of Kwara State Nigeria. PLoS Negl Trop Dis, 9 (7), e0003940. doi: 10.1371/journal.pntd.0003940.

[4] Alemayehu, B., Tomass, Z., Wadilo, F., Leja, D., Liang, S., \& Erko, B. (2017). Epidemiology of intestinal helminthiasis among school children with emphasis on Schistosoma mansoni infection in Wolaita zone, Southern Ethiopia. BMC Public Health, 17 (1), 587. doi: 10.1186/s12889-017-4499-x.

[5] Alicke, M., Boakye-Appiah, J. K., Abdul-Jalil, I., Henze, A., van der Giet, M., Schulze, M. B.,... Danquah, I. (2017). Adolescent health in rural Ghana: A cross-sectional study on the co-occurrence of infectious diseases, malnutrition and cardio-metabolic risk factors. PLoS One, 12 (7), e0180436. doi: 10.1371/journal.pone.0180436.

[6] Allen, A., Allen, S., Rodrigo, R., Perera, L., Shao, W., Li, C., Premawardhena, A. (2017). Iron status and anaemia in Sri Lankan secondary school children: A cross-sectional survey. PLoS One, 12 (11), e0188110. doi: 10.1371/journal.pone. 0188110 .

[7] Ayeh-Kumi, P. F., Addo-Osafo, K., Attah, S. K., Tetteh-Quarcoo, P. B., Obeng-Nkrumah, N., Awuah-Mensah, G., Asmah, R. H. (2016). Malaria, helminths and malnutrition: a cross-sectional survey of school children in the South-Tongu district of Ghana. BMC Res Notes, 9, 242. doi: 10.1186/s13104-016-2025-3.

[8] Ayogu, R. N., Nnam, N. M., Ibemesi, O., \& Okechukwu, F. (2016). Prevalence and factors associated with anthropometric failure, vitamin A and iron deficiency among adolescents in a Nigerian urban community. Afr Health Sci, 16 (2), 389-398. doi: 10.4314/ahs.v16i2.7.

[9] Bailey, R. L., West, K. P., Jr., \& Black, R. E. (2015). The epidemiology of global micronutrient deficiencies. Ann Nutr Metab, 66 Suppl 2, 22-33. doi: 10.1159/000371618.

[10] Buckley, G. J., Murray-Kolb, L. E., Khatry, S. K., Leclerq, S. C., Wu, L., West, K. P., Jr., \& Christian, P. (2013). Cognitive and motor skills in school-aged children following maternal vitamin A supplementation during pregnancy in rural Nepal: a follow-up of a placebo-controlled, randomised cohort. $B M J$ open, 3 (5). doi: 10.1136/bmjopen-2012-002000.

[11] Butler, S. E., Muok, E. M., Montgomery, S. P., Odhiambo, K., Mwinzi, P. M., Secor, W. E., \& Karanja, D. M. (2012). Mechanism of anemia in Schistosoma mansoni-infected school children in Western Kenya. Am J Trop Med Hyg, 87 (5), 862-867. doi: 10.4269/ajtmh.2012.12-0248.

[12] de Gier, B., Nga, T. T., Winichagoon, P., Dijkhuizen, M. A., Khan, N. C., van de Bor, M.,... Wieringa, F. T. (2016). Species-Specific Associations Between Soil-Transmitted Helminths and Micronutrients in Vietnamese Schoolchildren. Am J Trop Med Hyg, 95 (1), 77-82. doi: 10.4269/ajtmh.15-0533.

[13] Debalke, S., Worku, A., Jahur, N., \& Mekonnen, Z. (2013). Soil transmitted helminths and associated factors among schoolchildren in government and private primary school in Jimma Town, Southwest Ethiopia. Ethiop J Health Sci, 23 (3), 237-244.
[14] Desalegn, A., Mossie, A., \& Gedefaw, L. (2014). Nutritional iron deficiency anemia: magnitude and its predictors among school age children, southwest Ethiopia: a community based cross-sectional study. PLoS One, 9 (12), e114059. doi: 10.1371/journal.pone.0114059.

[15] Edinburgh, U. o. (2013). Systematic reviews and meta-analyses: a step-by-step guide. Research. Retrieved March 25th, 2018, from

http://www.ccace.ed.ac.uk/research/software-resources/systemat ic-reviews-and-meta-analyses.

[16] Ekpo, U. F., Omotayo, A. M., \& Dipeolu, M. A. (2008). Prevalence of malnutrition among settled pastoral Fulani children in Southwest Nigeria. BMC Res Notes, 1, 7. doi: 10.1186/1756-0500-1-7.

[17] Erismann, S., Knoblauch, A. M., Diagbouga, S., Odermatt, P., Gerold, J., Shrestha, A.,... Cisse, G. (2017). Prevalence and risk factors of undernutrition among schoolchildren in the Plateau Central and Centre-Ouest regions of Burkina Faso. Infect Dis Poverty, 6 (1), 17. doi: 10.1186/s40249-016-0230-x.

[18] Galgamuwa, L. S., Iddawela, D., Dharmaratne, S. D., \& Galgamuwa, G. L. S. (2017). Nutritional status and correlated socio-economic factors among preschool and school children in plantation communities, Sri Lanka. BMC Public Health, 17 (1), 377. doi: 10.1186/s12889-017-4311-y.

[19] Getaneh, Z., Enawgaw, B., Engidaye, G., Seyoum, M., Berhane, M., Abebe, Z., Melku, M. (2017). Prevalence of anemia and associated factors among school children in Gondar town public primary schools, northwest Ethiopia: A school-based cross-sectional study. PLoS One, 12 (12), e0190151. doi: 10.1371/journal.pone.0190151.

[20] Glinz, D., Silue, K. D., Knopp, S., Lohourignon, L. K., Yao, K. P., Steinmann, P., Utzinger, J. (2010). Comparing diagnostic accuracy of Kato-Katz, Koga agar plate, ether-concentration, and FLOTAC for Schistosoma mansoni and soil-transmitted helminths. PLoS Negl Trop Dis, 4 (7), e754. doi: 10.1371/journal.pntd.0000754.

[21] Godfred, E., Alatiah, G. A., Ayi, I., \& Steiner - Asiedu, M. (2017). Red palm oil bean-stew improved serum vitamin A and haemoglobin concentrations and anthropometric indicators of school children with low vitamin A concentrations in a malaria-endemic setting. African Journal of Food, Agriculture, Nutrition and Development, 17 (04), 12817-12836. doi: 10.18697/ajfand.80.16750.

[22] Goon, D. T., Toriola, A. L., Shaw, B. S., Amusa, L. O., Monyeki, M. A., Akinyemi, O., \& Alabi, O. A. (2011). Anthropometrically determined nutritional status of urban primary schoolchildren in Makurdi, Nigeria. BMC Public Health, 11, 769. doi: 10.1186/1471-2458-11-769.

[23] Greenland, K., Dixon, R., Khan, S. A., Gunawardena, K., Kihara, J. H., Smith, J. L., Kumar, S. (2015). The epidemiology of soil-transmitted helminths in Bihar State, India. PLoS Negl Trop Dis, 9 (5), e0003790. doi: 10.1371/journal.pntd.0003790.

[24] Grimes, J. E. T., Tadesse, G., Gardiner, I. A., Yard, E., Wuletaw, Y., Templeton, M. R., Drake, L. J. (2017). Sanitation, hookworm, anemia, stunting, and wasting in primary school children in southern Ethiopia: Baseline results from a study in 30 schools. PLoS Negl Trop Dis, 11 (10), e0005948. doi: 10.1371/journal.pntd.0005948. 
[25] Gupta, M., Gupta, B. P., Chauhan, A., \& Bhardwaj, A. (2009). Ocular morbidity prevalence among school children in Shimla, Himachal, North India. Indian J Ophthalmol, 57 (2), 133-138.

[26] Hall, A., Kassa, T., Demissie, T., Degefie, T., \& Lee, S. (2008). National survey of the health and nutrition of schoolchildren in Ethiopia. Trop Med Int Health, 13 (12), 1518-1526. doi: 10.1111/j.1365-3156.2008.02168.x.

[27] Hodges, M., Dada, N., Wamsley, A., Paye, J., Nyorkor, E., Sonnie, M., Zhang, Y. (2011). Improved mapping strategy to better inform policy on the control of schistosomiasis and soil-transmitted helminthiasis in Sierra Leone. Parasit Vectors, 4, 97. doi: 10.1186/1756-3305-4-97.

[28] Horiuchi, S., Paller, V. G., \& Uga, S. (2013). Soil contamination by parasite eggs in rural village in the Philippines. Trop Biomed, 30 (3), 495-503.

[29] Hussein, A. S. (2011). Prevalence of intestinal parasites among school children in northern districts of West Bank-Palestine. Trop Med Int Health, 16 (2), 240-244. doi: 10.1111/j.1365-3156.2010.02674.x.

[30] JBI, Q. s. U. (2015). CAN-SYNTHESIZE (M. B. H. Christina M. Godfrey Ed. 4.0 ed.): Joanna Briggs Institute.

[31] JBI, U. o. A. (2017). The Joanna Briggs Institute Critical Appraisal tools Retrieved December 27th, 2017, from http://joannabriggs.org/research/critical-appraisal-tools.html.

[32] Kattula, D., Sarkar, R., Rao Ajjampur, S. S., Minz, S., Levecke, B., Muliyil, J., \& Kang, G. (2014). Prevalence \& risk factors for soil transmitted helminth infection among school children in south India. Indian J Med Res, 139 (1), 76-82.

[33] Kepha, S., Nuwaha, F., Nikolay, B., Gichuki, P., Edwards, T., Allen, E., Brooker, S. J. (2015). Epidemiology of coinfection with soil transmitted helminths and Plasmodium falciparum among school children in Bumula District in western Kenya. Parasit Vectors, 8, 314. doi: 10.1186/s13071-015-0891-5.

[34] Korzeniewski, K., Augustynowicz, A., Smolen, A., \& Lass, A. (2015). Epidemiology of intestinal parasitic infections in school children in Ghazni Province, eastern Afghanistan. PakJ Med Sci, 31 (6), 1421-1425. doi: 10.12669/pjms.316.8889.

[35] Laxmi kant Khanal, S. R., Janak Sapkota, Dr. Achut Barakoti. (2011). Prevalence of intestinal worm infestations among school children in Kathmandu, Nepal. Nepal Med College Journal.

[36] Lwanga, F., Kirunda, B. E., \& Orach, C. G. (2012). Intestinal helminth infections and nutritional status of children attending primary schools in Wakiso District, Central Uganda. Int $J$ Environ Res Public Health, 9 (8), 2910-2921. doi: 10.3390/ijerph9082910.

[37] Mahmud, M. A., Spigt, M., Mulugeta Bezabih, A., Lopez Pavon, I., Dinant, G. J., \& Blanco Velasco, R. (2013). Risk factors for intestinal parasitosis, anaemia, and malnutrition among school children in Ethiopia. Pathog Glob Health, 107 (2), 58-65. doi: 10.1179/2047773213y.0000000074.

[38] Mekonnen, Z., Meka, S., Zeynudin, A., \& Suleman, S. (2014). Schistosoma mansoni infection and undernutrition among school age children in Fincha'a sugar estate, rural part of West Ethiopia. BMC Res Notes, 7, 763. doi: 10.1186/1756-0500-7-763.

[39] Mugono, M., Konje, E., Kuhn, S., Mpogoro, F. J., Morona, D.,
\& Mazigo, H. D. (2014). Intestinal schistosomiasis and geohelminths of Ukara Island, North-Western Tanzania: prevalence, intensity of infection and associated risk factors among school children. Parasit Vectors, 7, 612. doi: 10.1186/s13071-014-0612-5.

[40] Muller, I., Coulibaly, J. T., Furst, T., Knopp, S., Hattendorf, J., Krauth, S. J., Utzinger, J. (2011). Effect of schistosomiasis and soil-transmitted helminth infections on physical fitness of school children in Cote d'Ivoire. PLoS Negl Trop Dis, 5 (7), e1239. doi: 10.1371/journal.pntd.0001239.

[41] Mwanakasale, V., Siziya, S., Mwansa, J., Koukounari, A., \& Fenwick, A. (2009). Impact of iron supplementation on schistosomiasis control in Zambian school children in a highly endemic area. Malawi Med J, 21 (1), 12-18.

[42] Naotunna, N. P., Dayarathna, M., Maheshi, H., Amarasinghe, G. S., Kithmini, V. S., Rathnayaka, M., Agampodi, S. B. (2017). Nutritional status among primary school children in rural Sri Lanka; a public health challenge for a country with high child health standards. BMC Public Health, 17 (1), 57. doi: 10.1186/s12889-016-4001-1.

[43] Nepal, A. K., Gelal, B., Mehta, K., Lamsal, M., Pokharel, P. K., \& Baral, N. (2014). Plasma zinc levels, anthropometric and socio-demographic characteristics of school children in eastern Nepal. BMC Res Notes, 7, 18. doi: 10.1186/1756-0500-7-18.

[44] Nga, T. T., Winichagoon, P., Dijkhuizen, M. A., Khan, N. C., Wasantwisut, E., Furr, H., \& Wieringa, F. T. (2009). Multi-micronutrient-fortified biscuits decreased prevalence of anemia and improved micronutrient status and effectiveness of deworming in rural Vietnamese school children. Journal of nutrition, 139 (5), 1013-1021.

http://cochranelibrary-wiley.com/o/cochrane/clcentral/articles/ $872 / \mathrm{CN}-00683872 /$ frame.html

https://watermark.silverchair.com/1013.pdf?token=AQECAHi 208BE49Ooan9kkhW Ercy7Dm3ZL 9Cf3qfKAc485ysgAA AaAwggGcBgkqhkiG9 ${ }^{\text {w0BBwagggGNMIIBiQIBADCCAYI }}$ GCSqGSIb3DQEHATAeBglghkgBZQMEAS4wEQQM9A23 HqftYLkzIjTDAgEQgIIBU5nhvFe5MqLJeI4kIdfPqbh-cP1ku pA6Zw-_DqNLVKba7xLomlMUDLhuYGsL3SCEI7WGpme Y09fSicooFapRu2sKtLGIV6IyOA7sC3PRVetZkX7QuhEpid kU6riwwJy3aXpOpSL5H6rdAXBYUTxPEkv3JbiHpEw3XF9 j023wNo1Q_SjaPy2alNzlOjSJPdXqWpsQEJyqfU4ODdrdney LhHu4N75cmqe3esIIDZ6PaGf4Br4EqsYTXcA1mVvR9X6IT 9K_RKeuC-vvsU4AffOMN8kAWJmukpXSofACoSjCBd40q Ub $\overline{9}$ Ewcl KpFpMFrJsSeR WTfeaLWM1KMEhqPdWVD4m 84LQ6UxScL_VOrkRIsFVuMKyuqNstbX6pB-CtkAtfXG-7a 4TC6pXTHDjoOBba68xtliIw5AuLd mqc9VyBR5RU9qK d FX7EVjM68v-algcSZTCg doi:10.3945/jn.108.099754

[45] Nga, T. T., Winichagoon, P., Dijkhuizen, M. A., Khan, N. C., Wasantwisut, E., \& Wieringa, F. T. (2011). Decreased parasite load and improved cognitive outcomes caused by deworming and consumption of multi-micronutrient fortified biscuits in rural Vietnamese schoolchildren. American journal of tropical medicine and hygiene, 85 (2), 333-340. http://cochranelibrary-wiley.com/o/cochrane/clcentral/articles/ 529/CN-00798529/frame.html

https://www.ncbi.nlm.nih.gov/pmc/articles/PMC3144834/pdf/ tropmed-85-333.pdf doi:10.4269/ajtmh.2011.10-0651.

[46] Opara, K. N., Udoidung, N. I., Opara, D. C., Okon, O. E., Edosomwan, E. U., \& Udoh, A. J. (2012). The Impact of Intestinal Parasitic Infections on the Nutritional Status of Rural and Urban School-Aged Children in Nigeria. Int J MCH AIDS, $1(1), 73-82$. 
[47] Palmer, A. C., Schulze, K. J., Khatry, S. K., Luca, L. M., \& West, K. P. (2015). Maternal vitamin A supplementation increases natural antibody concentrations of preadolescent offspring in rural Nepal. Nutrition (burbank, los angeles county, calif.), 31 (6), 813-819.

http://cochranelibrary-wiley.com/o/cochrane/clcentral/articles/ 513/CN-01258513/frame.html

http://www.nutritionjrnl.com/article/S0899-9007 (14)

00516-4/pdf doi:10.1016/j.nut.2014.11.016.

[48] Papier, K., Williams, G. M., Luceres-Catubig, R., Ahmed, F., Olveda, R. M., McManus, D. P., Ross, A. G. (2014). Childhood malnutrition and parasitic helminth interactions. Clin Infect Dis, 59 (2), 234-243. doi: 10.1093/cid/ciu211.

[49] Prenkert, M., \& Ehnfors, M. (2016). Growth data of underprivileged children living in rural areas of Chin State, Burma/Myanmar, compared to the WHO reference growth standards: an observational study. BMJ open, 6 (1), e009119. doi: 10.1136/bmjopen-2015-009119.

[50] Rahman, A. S., Ahmed, T., Ahmed, F., Alam, M. S., Wahed, M. A., \& Sack, D. A. (2015). Double-blind cluster randomised controlled trial of wheat flour chapatti fortified with micronutrients on the status of vitamin $\mathrm{A}$ and iron in school-aged children in rural Bangladesh. Matern Child Nutr, 11 Suppl 4, 120-131. http://cochranelibrary-wiley.com/o/cochrane/clcentral/articles/ $514 / \mathrm{CN}-01134514 /$ frame.html https://onlinelibrary.wiley.com/doi/pdf/10.1111/men.12065 doi: $10.1111 / \mathrm{mcn} .12065$.

[51] Raihan Shrestha, M. M. (2013). Prevalence of intestinal helminth parasites among school-children of Bhaktapur district, Nepal. Nepalese Journal of Zoology.

[52] S. R. Tatala, C. M. K., L. H. Kyungu, U. Svanberg. (2008). Risk Factor for Anemia in Schoolchildren in Tanga Region, Tanzania. Tanzania Journal of Health Research, 10.

[53] Sah, R. B., Bhattarai, S., Yadav, S., Baral, R., Jha, N., \& Pokharel, P. K. (2013). A study of prevalence of intestinal parasites and associated risk factors among the school children of Itahari, Eastern Region of Nepal. Trop Parasitol, 3 (2), 140-144. doi: 10.4103/2229-5070.122143.

[54] Sarmila Tandukar, S. A., Nabaraj Adhikari, Anisha Shresth, Jyotshana Gautam, Binita Sharma, Deepak Rajbhandari, Shikshya Gautam, Hari Prasad Nepal, Jeevan B Sherchand. (2013). Intestinal parasitosis in school children of Lalitpur district of Nepal. BMC Res Notes.

[55] Sazawal, S., Habib, A., Dhingra, U., Dutta, A., Dhingra, P., Sarkar, A., Black, R. E. (2013). Impact of micronutrient fortification of yoghurt on micronutrient status markers and growth - a randomized double blind controlled trial among school children in Bangladesh. BMC Public Health, 13, 514. doi: 10.1186/1471-2458-13-514.

[56] Senbanjo, I. O., Oshikoya, K. A., Odusanya, O. O., \& Njokanma, O. F. (2011). Prevalence of and risk factors for stunting among school children and adolescents in Abeokuta, southwest Nigeria. J Health Popul Nutr, 29 (4), 364-370.

[57] Sousa-Figueiredo, J. C., Gamboa, D., Pedro, J. M., Fancony, C., Langa, A. J., Magalhaes, R. J., Nery, S. V. (2012). Epidemiology of malaria, schistosomiasis, geohelminths, anemia and malnutrition in the context of a demographic surveillance system in northern Angola. PLoS One, 7 (4), e33189. doi: 10.1371/journal.pone.0033189.

[58] Stewart, C. P., Christian, P., LeClerq, S. C., West, K. P., Jr., \& Khatry, S. K. (2009). Antenatal supplementation with folic acid + iron + zinc improves linear growth and reduces peripheral adiposity in school-age children in rural Nepal. Am J Clin Nutr, 90 (1), 132-140. doi: 10.3945/ajen.2008.27368.

[59] Sunish, I. P., Rajendran, R., Munirathinam, A., Kalimuthu, M., Kumar, V. A., Nagaraj, J., \& Tyagi, B. K. (2015). Impact on prevalence of intestinal helminth infection in school children administered with seven annual rounds of diethyl carbamazine (DEC) with albendazole. Indian J Med Res, 141 (3), 330-339.

[60] Tadege, B., \& Shimelis, T. (2017). Infections with Schistosoma mansoni and geohelminths among school children dwelling along the shore of the Lake Hawassa, southern Ethiopia. PLoS One, 12 (7), e0181547. doi: 10.1371/journal.pone.0181547.

[61] United Nations Children's Fund, W. H. O., World Bank Group. (2017). Joint child malnutrition estimates - levels and trends in child malnutrition. UNICEF Data.

[62] WHO. (2017, September 2017). Soil-transmitted helminth infections. Media Centre $>$ Fact Sheet. from http://www.who.int/mediacentre/factsheets/fs366/en/.

[63] WHO. (2018). Intestinal worms. What are intestinal worms (soil transmitted helminthiasis) ? Retrieved January 25th, 2018, from http://www.who.int/intestinal_worms/disease/en/.

[64] WHO. (2018). Micronutrient deficiencies. Nutrition. Retrieved March 24th, 2018, from http://www.who.int/nutrition/topics/ida/en/.

[65] WHO, U. (2004). Prevention and control of schistosomiasis and soil-transmitted helminthiasis Joint Statement.

[66] Yimam, Y., Degarege, A., \& Erko, B. (2016). Effect of anthelminthic treatment on helminth infection and related anaemia among school-age children in northwestern Ethiopia. BMC Infect Dis, 16 (1), 613. doi: 10.1186/s12879-016-1956-6. 